\title{
The Extent of Male Partners' Participation in Family Planning: A Case of Tarime District, Tanzania
}

\author{
${ }^{1}$ Zena Ismail Machinda, ${ }^{2}$ Prof. Mbonile J. M and ${ }^{3}$ Herrieth Godwin Mtae \\ ${ }^{1}$ St.Augustine University of Tanzania \\ ${ }^{2}$ University of Dar es Salaam, Tanzania \\ ${ }^{3}$ Open University of Tanzania
}

Corresponding author: zenatch@yahoo.com

\begin{abstract}
This study sought to examine the extent of male partners' participation in family planning in Tarime District, Tanzania. The study adapted a mixed research design to generate data through in-depth interviews, focus group discussions and questionnaires. The instruments were employed to 312 respondents. The analysis was done using descriptive statistics and thematic approach. The major findings indicated that men were the major decision makers within the household because in many situations, they owned the family income and they were the breadwinners. Study participants had different perceptions of family planning methods but generally, fear of side effects was found to be the major hindrance to enhanced use of family planning methods. Furthermore, some people associated the use of family planning with unfaithfulness or promiscuity. The study recommends that it is important to consider the multiplicity of social realities in the efforts to improve the acceptability of the modern family planning services. In addition, efforts need to be intensified to encourage partner communication and engagement in order to improve the family planning practices. Future family planning programs should look at addressing underlying social norms leading to gender inequality and lack of joint decision-making. Finally, family planning programs should encourage communication and joint decision-making among couples in households.
\end{abstract}

Keywords: Decision-making, spousal communication, family planning practice, contraceptives

\section{Introduction}

Sub-Saharan African countries have low rates of contraceptive use and high rates of women who want to stop or delay childbearing without using any family planning (FP) (Westoff, 2001; Bongaarts 1995 cited by Kakoko et.al 2013). Individuals and couples who want to limit their fertility are often unable to obtain the family planning methods they prefer to use due to certain barriers (Campbell et al. 2006). These barriers include cost of contraceptives, distance from home to the clinic, poor services, medical restrictions and fear of side effects or even misinformation. According to Sedgh et al, (2007), available literature explains that money is the primary factor that inhabits the family planning practice while other factors include fear of side effects. Darroch et al (2011) argued that about 59\% of unintended pregnancies by couples could be reduced if factors related to unused family planning methods were overcome; For instance, in the Colombia Demographic and Health Survey 20042005 (2005). 21\% of married women who wanted to delay childbearing but did not use any contraception cited health problem or side effects as their reason for non-use while $10 \%$ cited cost/access and none cited lack of knowledge. In Uganda, for example, $25 \%$ of married women none-users cited health / side effect as the reason for non-use, $20 \%$ cited financial cost/ access and the remaining 55\% reported lack of knowledge (Uganda Demographic and Health survey (Uganda Bureau of Statistics (2001). Similar trends were shown in Asia, South America and Africa (Sedgh et. al.2007).

The Total Fertility Rate (TFR) in Tanzania is 5.4 people, which is relatively high. It is observed that 
only $34 \%$ of currently married women in Tanzania use some method of family planning. Out of these, $27 \%$ use modern methods and $7 \%$ rely on traditional methods. The most commonly methods preferred by married women in Tanzania are injectables, pills and female sterilization (United Republic of Tanzania, 2010).

The maternal death rates in Tanzania are among the highest in sub Saharan Africa. The 2015-16 (TDHS) estimated maternal deaths at 556 deaths per 100,000 live births with the figure in the rural areas being higher than in urban centres. The use of family planning is one of the possible means to reduce maternal death. This is because family planning reduces deaths due to unintended pregnancy and abortion, regardless of the legal status of the operation. However, the use of family planning has been low, particularly so among men (United Republic of Tanzania, 2016).

Involving men and obtaining their support and commitment to family planning is crucial, especially in Africa, where men have an elevated position in the society. Men make most decisions that affect political life. They hold positions of leadership and influence from the family unit right through the national level (Chuwa 2013). Male involvement in family planning program would therefore not only help to accelerate the responsibility of family planning decision-making for women, but also ease the understanding and use of contraceptive in general.

The family planning program in Tanzania has had an inadequate focus on men for the reasons that are not well known. Consequently, little is known on men's knowledge and practice on family planning even though Tanzanian men typically have more say than women in decision-making in the use of contraception and in the number of children to have by the couple. Based on the social-cultural and system dynamics, the importance of access to and right use of family information among population groups at local context in Tanzania is justified (Kakoko et al 2013).

Based on this background, the study investigated on the extent of male partners' participation in Tarime District. In Tanzania, there are several studies on male participation in family planning which have been conducted by different authors in different settings. For example, Chuwa (2013) reported that most family planning services are offered within reproductive and child health clinic $(\mathrm{RCHC})$ and most researches and information campaign focused on women. The focus on women has reinforced the belief that family planning is largely a women's role, with the man playing a peripheral part. In Tanzania, male participation in reproductive and child health services is low, estimated at $5 \%$ and it is lower in urban areas than in rural areas. Barriers said to inhabit men participation in these services are lack of information, fear of HIV-test results and limited time to spend at clinic. Other barriers often cited are social and religious norms that prohibit men from attending women's health clinic and the widespread attitude that women reproductive health is not a man's responsibility (Family Health International, 2012).

Men's participation in reproductive health is very crucial to the success of family planning programs and women's empowerment. However, low choice and access to methods, attitudes towards contraceptive use, fear of side effects and poor quality of services available, cultural and social economic factors as well as gender-based barriers are some of the reasons for low utilization of family planning services in the study area (Akufuah 2008; Zamawe 2015 as cited by Itika 2015). The Government of Tanzania through the Ministry of Health and Social Welfare has done more efforts to provide comprehensive health services to all citizens. This is recognized, among others, through the formulation of the Health Policy in 2002, aimed at providing direction towards improvement and sustainability of health status of all the people, by reducing disability, morbidity and mortality, improving nutrition status and raising life expectancy (United Republic of Tanzania, 2002).

Despite the multilateral initiatives and efforts being made towards family planning intervention program at Tarime District, still fertility rate is relatively high above 5 children per women. Contraceptive prevalence rate was relatively low with $6.3 \%$ in 2017 as well as modern contraceptive rate scoring $24 \%$ in 2017 (Tanzania District Health Information System 2,2018 ). In connection to the policy, the utilization of contraceptive methods is inseparable with good health of the citizens since good health is a major resource of poverty eradication and economic development. With all these efforts, the problem still persists and that is why this study sought to identify the extent of male partners' participation in family planning practice in Tarime District, Tanzania. Tarime district scored the lowest contraceptive prevalence rate $(C P R)$ in the region ranging from 
$5.7 \%$ in 2015, $7.9 \%$ in 2016 and $6.3 \%$ in 2017 compared to other districts. In the near past, the contraceptive coverage by modern method increased as follows: $18.5 \%$ in 2015, $27.7 \%$ in 2016 and 24\% in 2017 (DHIS2 field 2018). Furthermore, the area experiences strong social-cultural practices such as patriarchy, female genital mutilation (FGM), "Nyumba Ntobhu. Nyumba Ntobhu is a local practice where by a little girl can 'get' marriage to an older woman (same sex), live together, sleep together, raise children together and promise to stay together, just like people of different genders. Then a girl is exposed to make sex with a man of her choice in order to get pregnancy but the child/children raised will be the property of the order woman.

Several studies have been carried out around the world on decision- making towards family planning. For example, Bayray (2012) states three approaches of decision-making: joint decisions, male dominated decisions and female dominated decisions. As highlighted, male dominated decisions were the norms across female and male participants, followed by joint decision-making and last, femaledominated decisions. According to Ogunjuyigbe et.al (2002), more than half (56\%) of men in Ethiopia reported no discussion with wives on issues related with family planning use and believed that it is a natural process and needs not to be discussed. However, $44 \%$ believed discussion on these issues should be always initiated in the family. Similarly, 67 $\%$ of them reported that decisions are to be taken jointly with wives, while $21 \%$ felt that all decision related to family planning should be taken by wives alone. Another $12 \%$ felt that elder family members and relatives external power should decide.

The lack of understanding surrounding what influences family planning use and how decisionmaking takes place in families has led to the inability of policy and programs to focus on the factors that are most important to helping people control their fertility (Campbell et al. 2006). In Nigeria, consistently, less than a quarter of men individually initiated decisions on such issues as when achieving pregnancy, when to avoid pregnancy and the use of contraceptives (Cleland et.al 2011; ljadunola et.al 2010). Despite the clear association between couple discussion and use of family planning, little is known about how male partners' participate in family planning through decision-making.

Frost et al. (2008) reported that discussion between partners may influence choice of contraceptive type and frequency of their use. Contraceptive services are frequently geared toward females while males are often the ones who are the primary decisionmakers on number of children to have and their partner's use of contraceptive method (Nzioka, 2002; Oyediran et al 2002; Soldan, 2004 cited by Kakoko et al 2013). Furthermore, couples disagreement is a barrier of communication about contraceptive use in the family. This is because females might fear of initiating a difficulty discussion about contraception (Kakoko et al. 2013).

Determinants of spousal communication are varied and complex. In sub-Saharan Africa, for example, in Tanzania, Ida (2013) revealed that, gender, roles and norms are specifically salient features, shaping couple communication and subsequent contraceptive use. Spousal communication helps couples to be aware of each other's perspective about family size and composition so that consensus can take place about the contraceptive to use. Those who communicate with their wives are more predisposed towards the use of contraception (Itika, 2015). Since marital fertility involves participation of the wife and husband, who may differ in their reproductive goals (in terms of number and sex of children and timing of having the children), successful planning and decision-making about fertility size and use of contraceptives requires effective communication between both marital partners (Mtae, 2018). Therefore, findings of this study are expected to contribute insights on the potential interventions that could be designed to further promote the appropriate family planning measures.

\section{Research Methodology}

This section explains about the methodology that guided the study. It presents items including research design, population and sampling, instrumentation, data collection procedures, data analysis and ethical considerations.

\section{Research Design}

The study adopted the mixed research design. According to Cresswell (2009), mixed research design focuses on collection, analysis and combination of both qualitative and quantitative data in a single study. The two research approaches complement each other, providing different perspectives and answering different specific questions within any one broad area. The use of the two approaches also enables validation of data through triangulation. 


\section{Population and Sampling}

Population is the group of people under which the study is to be conducted. The respondents in this study comprised of three hundred and twelve participants (204 females and 108 males). Purposive sampling technique ensured that participants with the right information on family planning practice were chosen. Participants were from different categories (family planning coordinators, women group leaders, religious leaders, opinion leaders and local government leaders). They were chosen to give their views related to male partners' participation in family planning services.

\section{Instrumentation}

Open and closed ended questionnaires and interview guides were used to collect data. Cohen, Manion and Morrison (2007) argued that a questionnaire is widely used and is a useful instrument for collecting information. For the purpose of this study, the questionnaire was chosen because it catered for a large number of participants and guaranteed their anonymity. Questionnaires can be administered without the presence of the researcher and it is often easy to analyze the data. The questions in the questionnaire focused on decision making about family planning practices and spousal communication on family planning practice.

\section{Data Collection Procedure}

The researchers distributed the questionnaire to each participant and asked them to complete and for those who did not know how to read and write, they were assisted by the four research assistants. This was done to allow and make sure that participants might give their opinion on the theme under the study. All three hundred and twelve participants were able to complete questionnaires. In depth interview and focus group discussion were done with twelve key informants including family planning coordinator, religious leader, women leader, ward executive officer and opinion leader.

\section{Statistical Treatment of Data}

Phondje et al (2011) describes data analysis as "examining, sorting, categorizing, evaluating, comparing, synthesizing and contemplating the coded data as well as reviewing the raw and recorded data. This is an important stage where all data is brought together and grouped according to their similarities and themes. Most data collected were quantitative in nature. These data were tabulated and calculated in percentages to find out the underlying meaning of the information collected. The qualitative data were subjected to content analysis through the thematic approach.

\section{Ethical Considerations}

To carry out the study, permission was obtained from the Mara Region and Tarime District administration. The participants were informed about the expectations and procedure of the study and they consented voluntarily. The researcher assured the respondents a high degree of confidentiality regarding the information provided. They were also informed that they could withdraw from the study at any time (Cresswell 2013).

\section{Findings and Discussion}

The purpose of the study was to investigate the extent of male partners' participation in family planning practice. The findings are presented into various themes as follows:

\section{Decision making on financial consequences in relation to family planning side effects}

Men who perceived that family planning had side effects were also concerned about the financial implications for treating their wives once they experienced family planning side effects. In this fact, men, especially from rural areas, argued that they were poor and did not have enough money to pay for treatment incase their wives suffered from family planning side effects. Some men argued that the government should set aside money for treating their women who experienced family planning related side effects. They pointed out that male disapproved using family planning method because of financial repercussion from treating their wives if they experienced family planning side effects, thus, they were reluctant to make decision to practice family planning methods.

\section{Whether Family Planning should be the decision making of male within the family \\ With regard to decision making, majority of interviewed males (82.8\%) and females (83.3\%) reported that using contraception should not be the decision of males; whiles $17.2 \%$ of females and $16.7 \%$ of males believed that, it should be the decision of males.}

Findings from focus group discussion revealed that, male involvement is necessary because they were breadwinners of many homes hence there was the need for their involvement to support their partners financially. 
Furthermore, through discussion about family planning issues with their partners, women would be in the position to choose the best method to suit them. Others also thought that involving men in family planning would help involve family planning coverage, since men are the decision makers in most families (FGD, female, rural, 35-49 years).

\section{Perception of family planning method side effects}

In the FGD, males and females were both concerned about the side effects which they feared could occur due to the use of family planning (FP) methods. The extreme side effects mentioned are the result of myths/misconceptions within the community. Males mentioned minor side effects such as headaches, bleeding, weight gain, weight loss, nausea, dizziness and stomach-ache. On the other hand, they pointed out severe side effects such as infertility, cancer and birth deformities including physical and mental handicaps. For example, one male commented:

...Women have irregular periods after using contraception. In addition, once a woman uses contraception, she can later on give birth to a mentally-retarded child or one with missing organs like eyes or arms... the woman can give birth to a child who looks like an animal or like a goat (FGD, males, rural, 30-49 years).

Another man had this to say: These FP methods spell trouble for women and our families. For example, if an implant is inserted into a woman's arm, then she is told not to do hard work such as farming. I wonder how that woman will survive while she earns her food through farming.... It is better that women should not use FP methods because it will make our lives poor (FGD, males, semi-urban, 30-49 years).

Similar sentiments on the side effects of family planning were pointed out in another FGD. One man said: These family planning methods have side effects on our wives... some of women suffered from uterine tumors, cancer and irregular periods when they used family planning methods (FGD, males, semi-urban, 18-30 years).

Women also raised some concern. One female discussant, for instance, said: $F P$ methods have some side effects to women. When I used FP injection for about three years, I started overbleeding for three months...I was so scared... and I stopped using them. Also, one of my friends who was using injections (Depo-Provera) suffered from uterine tumors. I also heard that FP methods can cause cancer (FGD, females, rural, 18-30 years).
Similarly, one of the IDIs informants said that they feared the side-effects caused by some of the FP methods: I used oral pills and started getting my periods irregularly. I went to the hospital and changed into an implant. I suffered from heavy periods and headache... Again, I went to the hospital and opted for an injection. Since then, I have no problem. .. (IDI, female, urban, 34 years).

\section{Spouses' communication on the desired number of children}

While communication among couples is important in family planning and decision making on the number of children a couple wants to have, in rural areas, there was little or no communication among couples on the use of FP and desired number of children. One participant said: In rural areas, many couples do not discuss about family planning because the majority of them lack knowledge (FGD, males, urban, 30-40 years). In addition, the finding shows that, some people believed that discussing family planning issues with their partners was not important. For example, one woman had this to share: Most people in rural areas do not discuss family planning issues with their partners. Some men believe that it is not an important thing to them. Other men believe that it is the responsibility of women and that is why they do not discuss it (FGD, female rural, 30-49 years).

Moreover, the findings show that it was difficult for women to engineer discussions as they perceived that men should largely make key family decisions. One woman commented: Men are decision makers in the households including on the number of children to have and family planning use or not to use (FGD, female, rural, 18-29 years). Likewise, the finding from an in-depth interview (IDIs) shows that most couples discuss the family planning use because of economic hardship. People want to have manageable families they can afford to take care of. One key informant said: It is normal nowadays for couples to discuss family planning issues. Life nowadays is had and people want to have the right number of children they can take care of. People do not want to have children who will turn into street children (IDI, male, urban, 39 years). In addition, findings show that relatives had influence on the number of children a couple might have. Relatives, especially mothers in laws, could put pressure on their sons or daughter-in-laws to have more children than they had initially planned to have. 


\section{Urban/rural differences on value of children and use of family planning}

In rural areas, men expressed preference for large families and perceived family planning method as tools for controlling the number of children contrary to their preferences. Some woman said that, men wanted to have many children, and hence perceived them as reluctant to allow their wives to use family planning methods. As one discussant explained: I think, some men want more children than their wives. For instance, I wanted four children but my husband wanted more (FDG, female, urban, 30-49 years).

Unlike in urban areas, people in the rural areas prefer many children because the children helped them with farming activities. In fact, children in rural areas were generally treated as sources of labour for families. Social norms in rural areas favored having as many children as possible because of the extended family support system that allowed the children to stay with relatives. One woman commented; ...Ten children can participate in farming activities and produce more than a person with two children (FGD, females, rural, 18-29 years). In addition, findings show that relatives had influence on the number of children a couple might have. Relatives, especially mothers in law could put pressure on their sons or daughter-in-laws to have more children than they had initially planned to have. For example, one woman said: Sometimes we are afraid to discuss about FP with our husbands because some mothers in law had made it clear that they want their sons to have as many children as possible. We are afraid to go against our mothers in laws ... for that matter; we do not discuss FP with our husbands (FGD, females, urban, 18-29 years).

In urban areas, on the other hand, the value of children was seen in terms of costs involved in raising them, especially in terms of school, medical services and other social amenities. Moreover, in the urban areas, everything was paid in monetary terms ranging from renting houses, buying food and other amenities. Thus, having more children would mean incurring more costs. Furthermore, one key informant commented: Nowadays, people know the importance of using FP because life is hard. People want to have children whom they can manage to take care of (IDI Urban, male, 39 years,).

\section{Discussion}

The study aimed at establishing the extent of male partners' participation in family planning practices.
From the study, various themes emerged. Study findings revealed that family planning was not only about child spacing and birth control, but also about the social, economic and cultural aspects of the society.

In this study, perceptions on different kinds of risks came forward as relevant to family planning and as having an influence on family planning use and communication among couples in the households. The anticipated side effects, as depicted in this study, imply that financial costs would be involved in treating perceived side effects. These side effects worried some women, especially those who are too poor to afford to pay for the medical treatment. Generally, these women relied on their husbands to pay for their medical treatments, as they did not have their own money.

Furthermore, women also considered the social risks of being labeled as unfaithful by using family planning methods. Fear of social risks could lead to low or non-use of family planning among women and therefore, prevented women from discussing family planning with their husbands. This finding is in line with that of Kaida et al. (2005) in Uganda, where contraceptive use was commonly associated with promiscuity and infidelity. Also in Ghana, contraceptive use was associated with promiscuity (Kakoko et al 2013) whereby sixty percent of women agreed with the statement that women who use contraception may become promiscuous (Kakoko et al 2013).

The different kinds of risks on family planning were gendered in the sense that men and women spoke of different kinds of risks. Men worried about the financial costs and health risks to their wives, as well as the health status of their children. Women, on the other hand, were worried about side effects and the risk of being accused of promiscuity. This mismatches or disconnects on family planning affected the couples' family planning communication. As a result, there was little or no communication between husbands and wives on family planning issues, which in turn led to low or non-use of family planning methods. This lack of joint decision-making among couples on family planning corroborates with the study by Mwageni et al. (1998) cited by Kakoko 2013), which found lack of joint decision-making on family planning issues among the couples in Mbeya, Tanzania. 
The findings of this study revealed some disparities in gender relations, particularly when it comes to decision-making in the households among couples on the use of family planning and the number of children to have. In addition, women in urban areas expressed freedom to initiate a discussion on family planning without fear of being labeled as unfaithful wives. This could be caused by information and education more readily available in urban areas as compared to rural areas. The high cost of living in urban areas made couples think twice about the costs of bringing a child into the world. In rural areas on the other hand, children are perceived as assets to work on farms, hence the more children one has the better the position in the society.

Furthermore, the study found that there was limited communication among the couples, especially in rural areas about family planning and to some extent this contributed to secret practice of family planning. The absence of communication might have been caused by the prevailing cultural stereotypes that only men should initiate the discussion of family planning since they are the bread- winners and they paid the bride prices when they married. In rural areas, lack of communication could be attributed to the dictates of patriarchal system where living in a male-dominated society makes such discussion out of bounds for some couples (Khan et al. 2002). Additionally, inequality in gender relations among the couples can lead to poor health outcomes by hindering communication between partners about reproductive health decisions by constraining women's access to reproductive health services, by preventing women's and men's attainment of sexual health and pleasure and by increasing their risk of contracting HIV infection and other STIs (Population council and interagency 2002 as cited by Kakoko 2013).

The study found that there was more communication among couples in urban areas than among couples in rural areas. Causal factors included association of family planning use with infidelity, especially among the females or lack of adequate information on the importance of using family planning as well as cultural factors that limited the discussion of sexual matters especially among rural couples. Perceived association of FP with infidelity in this study corroborates with the findings in Ghana where contraceptive use was commonly associated with perceived infidelity among women (Casterine et al 1997 as cited by Kakoko et al 2013).

\section{Conclusion and Recommendations}

This section gives the conclusions of the study and then comes up with the recommendations.

\section{Conclusions}

Study participants had different perceptions of family planning methods. Generally, fear of side effects was found to be the major hindrance to enhanced use of family planning methods. Furthermore, some people associated the use of family planning with unfaithfulness or promiscuity.

\section{Recommendations}

This study recommends that it is important to consider the multiplicity of social realities in the efforts to improve the acceptability of the modern family planning services. In addition, efforts need to be intensified to encourage partner communication and engagement in order to improve the family planning practices. Future family planning programs should look at addressing underlying social norms leading to gender inequality and lack of joint decision-making. Finally, family planning programs should encourage communication and joint decision-making among couples in households.

\section{Reference}

Bayray, A (2012): “Assessment of Male Involvement in Family Planning Use Among Men in South Eastern Zone of Tigray, Ethiopia. Scholarly Journal of Medicine 2 (2): 1-10.

Campbell $M$, Nuriye NS, Malcolm P: Barriers to fertility regulation. A review of the literature. Stud Fam Plann. 2006, 37 (Suppl 2): 87-98.

Chuwa, M. (2013). Male Involvement in Family Planning Practice, African Journal of Midwifery and Women's Health. https://dol.org/10.12968/ajm 2012/60. 3.132. Accessed November 19,2020.

Cleland, J.G., Ndungwa R.P., \& Zulu E.M. (2011): Family Planning in Sub- Saharan Africa: Progress or Stagnation? World Health Organization; 89(2):137-143.

Cohen, Manion and Morrison K (2007): Research Methods in Education. London: Rutledge.

Colombia Demographic and Health Survey: Profamilia, Macro International, Inc. Colombia Demographic and Health Survey 2004-2005. (2005). Calverton, United 
States: Macro International, Inc.

Cresswell, J. W. (2009). Qualitative inquiry and research design: Choosing among five approaches $\left(2^{\text {nd }} \quad\right.$ e.d). Thousand Oaks: Sage Publications.

Cresswell, I. W. (2013).Qualitative inquiry research design. Choosing among five approcheses,(3th ed). NewYork.Sage Publications.Doi10. 1080/0971923.2011:11892935.

Darroch,J.E, Gildas, Haley, B, (2011): Contraceptive Technologies: Responding to women needs. New York: Guttmacher. Institute.

Family Health International (2012): Increase Male Involvement in Family planning. Thaak Hand India Resarch Triangle Park. USA.

Frost J.J,Darroch J.E (2008): Factors associated with contraceptive choice and inconstisted method use, United State. Perspective Sex Reproductive Health. 40: 94-104

http://www.biomedcentral.com/1471-

$2458 / 13 / 523$

Ida, M (2013).Family Planning Decisions, Perceptions and Gender Dynamics AmongCouples in Mwanza, Tanzania: A Qualitative Study.

ljadunola,MY,Abiona TC,ladunola KT,Afolabi, OT,Esimai OA,Olaolorun FM (2010):Male involvement in family planning decision making in Ile-Ife, Osun-States of Nigeria. Afri J Reprod. Health.14 (4) 43-50.

Itika, A (2015), The Participation of Married Men in Decision-Making on Households' Family Planning Methods in Mbeya City. (Unpublished)

Kaida A, Kipp.W, Hessel.P, Konde-lule,J: Male participation in family planning: results from a qualitative study in Mpigi district, Uganda. Biosoc Sci. 2005.37:269-286.

Khan,M F ,Townsend J.W Costa S (2002):Behind closed doors: a qualitative study of sexual Behaviour of married women in Bangladesh,Cult Health Sex.4:237256. 10.1080/13691050110102253.

Kakoko, D, Mosha, I and Ruben, R (2013): Family Planning Decisions, Perceptions and Gender
Dynamics among couples in Mwanza, Tanzania: A qualitative study: BMC Public Health.Vol. no.13. 523.

Mtae,H.G, (2018). Fertility Preferences in Tanzania. Assessment of Determinants of Couples' Decisions on Fertility Preferences in Kishapu and Mvomero District, Tanzania. Wandersbeck, South Africa, 3631.

Nzioka C: Programming for male involvement in reproductive health. Report of the meeting of WHO Regional Advisors in Reproductive Health, WHO/PAHO. 2002, Geneva, Switzerland: World Health Organization.

Ogunjuyigbe,P O. (2002) Spousal communication, changes in partner attitude and contraceptive use among Yorubas of South West Nigeria. J Soc-Sci: 6 (1) 59-6

Oyediran K, Isiugo-Abanihe U: Husband-wife communication and couple's fertility desires among the Yoruba of Nigeria. Afr Popul Stud. 2002, 17: 61-80.

Phondje, W., Kittisarn, A. \& Neck, P. A. (2011). The Seven Steps of Case Study Development: A Strategic Qualitative Research Methodology in Female Leadership Field. Review of International Comparative Management, vol. 12 (1), pp. 123 - 134. Retrieved from https://www.academia.edu/4793339/The_S even_Steps_of_Case_Study_Development_ AStrategic_Qualitative_Research_Methodol ogy_in_Female_Leadership_Field.

Sedg, G., Hussain, R., Bankole, A., and Singh, S. (2007). Women with an unmet need for contraception in developing countries and their reasons for not using a method.

Guttmacher: Institute. From https://www.policyarchive.org/handle/1020 7/5945.

Tanzania District Health Information System 2 (2018). Uganda Bureau of Statistics (UBOS) and ORC Macro: Uganda Demographic and Health Survey 2000-2001.2001, Calverton,. Maryland, USA: UBOS and ORC Macro.

Uganda Bureau of Statistics (UBOS) and ORC Macro: Uganda Demographic and Health Survey 2000-2001. 2001, Calverton, Maryland, USA: UBOS and ORC Macro 
United Republic of Tanzania (2010) Tanzania demographic and health survey, National Bureau of Statistics, Dar Salaam, Tanzania and ICF Macro Calverton, Maryland, USA.

United Republic of Tanzania (2002), Tanzania demographic and health Survey. National Bureau of Statistics: Dar Salaam, Tanzania and ICF Macro Calverton, Maryland, USA.

United Republic of Tanzania,(2016). Tanzania

demographic and health survey and malaria indicator survey (2015-2016). Final Report. Ministry of Health, Community Development Gender, Elderly and Children, Dar es Salaam. National Bureau of Statistics, ICF, Rockville, Maryland USA.

Westoff CF: Unmet need at the end of the century. DHS Comparative Reports No. 1. 2001. 2001, Calverton, Maryland: ORC Macro. 